\title{
Building Peace in the Shadows of a Predator State: Unpacking the Work of the National Peace and Reconciliation Commission (NPRC) in Zimbabwe
}

\author{
Ched Nyamanhindi \\ Africa University, Institute Of Peace, Leadership And Governance \\ DOI: 10.29322/IJSRP.11.01.2021.p10994 \\ http://dx.doi.org/10.29322/IJSRP.11.01.2021.p10994
}

\begin{abstract}
This paper analyses the healing and reconciliation policy in Zimbabwe as embodied by the National Peace and Reconciliation Commission (NPRC). Zimbabwe has a history of cosmetic attempts at healing and reconciliation dating back to the 1980s. Informed by secondary data, the paper explores the strengths and flaws of the current healing and reconciliation policy. It argues that political reforms in Zimbabwe are a prerequisite for peace and reconciliation. With the alleged perpetrators of the atrocities still in power, the ideals of justice, peace, healing and reconciliation are difficult to achieve.

The NPRC remains an excellent blueprint but without political will, an adequate budget, effective visibility, survivor inclusion, truth telling, justice and unity the policy will be ineffective. The inclusion of stakeholders such as traditional leaders, faith based organisations, civic society and survivors are crucial for the effectiveness and sustainability of the process. For Zimbabwe to have an effective healing and reconciliation process a balance must be found between retributive justice and reconciliation. Transformative and restorative justice is best suited for the Zimbabwe scenario due to the political power dynamics, history of violence and previous failed attempts at reconciliation. This approach will result in restoring affected communities and the involvement of different stakeholders.
\end{abstract}

Index Terms- policy, healing, reconciliation, justice, peace

\section{INTRODUCTION AND BACKGROUND}

$\mathrm{T}$ he healing and reconciliation policy in Zimbabwe continue to be impractical due to a myriad of challenges. Zimbabwe has a history of conflict and violence dating back to the liberation struggle against the white colonialism and throughout the post independence era. Between 1982 and 1987 supporters of Zimbabwe African People's Union (ZAPU) in Matebeleland and Midlands were killed by the Korean trained Fifth brigade. The supporters were mainly Ndebeles and according to the Catholic Commission of Justice and Peace (1997) about 20000 civilians lost their lives in what has become known as Gukurahundi. The country experienced a cycle of high-level conflicts such as the seizure of white-owned farms in 2000, Operation Restore Order in 2005 , electoral conflict in 2008. These conflicts resulted in the killings of scores of people, injuries, rape and sexual assault and the destruction of property. Zimbabwe continues to be in vicious cycle of political violence and in a war paradigm. Machakanja (2010) reiterates that, "Zimbabwe has been trapped in a complex and protracted political crisis that has seen rising levels of humanrights violations, including kidnappings, disappearances, arbitrary detentions, torture, sexual violence and the forced recruitment of youth by armed groups, to name just a few."

The Gukurahundi conflict for example, became a multifaceted conflict that revolved around issues of power, interests and resources. The conflict became entrenched deriving its roots from colonial times and involving several parties within and outside Zimbabwe. Healing and reconciliation efforts to address conflicts in Zimbabwe have faced numerous challenges. The Unity According of 1987 mainly addressed the issues of the perpetrator and totally ignored the victim. It was an agreement between leaders of two political parties neglecting to address the majority that had suffered in Matebeleland and Midlands. NdlovuGatsheni, (2012) notes that the Unity accord brought relief nationwide, but in parts of the country it has left a behind many problems which remain unsolved to this day. These include poor health, poverty, practical and legal problems and a deep rooted suspicion of Government officials.

The Organ on National Healing, Reconciliation and Integration set up by the Inclusive Government in 2008 did not achieve the expected outcomes. It was undermined by ethnic and political factors which proved an obstacle to national healing. With Mugabe and his allies who committed the atrocities at the helm of the government, there was no state commitment to reconciliation and justice. The 2013 Constitution gave birth to the National Peace and Reconciliation Commission (NPRC) with the aim to spearhead peace and reconciliation issues in Zimbabwe.

\section{THEORISING Transitional JUSTICE}

Transitional Justice is a subject area that is highly undertheorised. Although there have been activities conducted globally and the reverberant academic debate on the topic, there are few attempts to conceptualise transitional justice theoretically (Susanne Buckley-Zistel, Teresa Koloma Beck, Christian Braun and Friederike Mieth, 2014).

Transitional Justice Discourse and practice are largely based on Western thinking that is strongly influenced and shaped by historical experiences. The events and experiences that have influenced the development of Transitional Justice include the 
Nuremberg and Tokyo trials after the Second World War, the change from dictatorship to democracy in South America, international criminal tribunals in the former Yugoslavia and Rwanda, and the Truth and Reconciliation Commission (TRC) in South Africa. There have been attempts to theorise Transitional Justice with the focus on justice and transition. Catherine O' Burke (2013) assesses what a transition should achieve, the type of society that must be birthed, how a transition can be accomplished and how gendered citizenship can be achieved after a transition. Aiken (2013) argues that the aim of a transition is the transformation of the antagonistic relationships between the parties to the conflict through transitional justice leading to reconciliation. Other scholars advance the view that transitional should lead towards liberal values and democracy (Teitel 2003; Mihr 2012). For Oomen (2005) the rule of law remains a paramount objective in the transitional processes.

Scholars that lean on the notion of justice outline different understandings of the matter. Justice is viewed as punitive, corrective, restorative, reparative or distributive. Lambourne (2009) discusses the linkages between the different types of justice for example retributive, restorative and distributive justice. Justice is views as aiming to promote just peace and protecting human rights (Mani2002, May 2012). Efforts to theorise Justice have also focused on the inclusion of economic, social and cultural rights in addition to political and civil rights (Laplante 2008; Mani 2008; Miller 2008).

Theoretical this paper challenges the notion that Transitional Justice is a global norm. Nagy (2008) suggests that Transitional Justice can be perceived from a local situation. The concepts of justice, truth and reconciliation can mean different things to different people and societies. The NPRC must therefore draw lessons from the vast experiences and events of Transitional Justice and come up with a solution tailor-made for the Zimbabwe situation. The alleged perpetrators of atrocities in Zimbabwe still control power making Retributive Justice almost impossible. The NPRC must therefore find a balance between Retributive Justice and Restorative Justice to achieve sustainable peace and reconciliation.

\section{POLICY PROBleM}

The foundation of Zimbabwe's peace and reconciliation policy is flawed. The policy is first and foremost created by a government that is perceived as the chief perpetrator of the various conflicts experienced in the country. Hence the policy is viewed as the creation of the perpetrators trying to achieve reconciliation by evading justice and accountability. The perpetrators live lavishly whilst the victims live in poverty and emotional torture. The government is viewed as unwilling to engage honestly and genuinely with the past as some of the senior government officials are implicated in the atrocities. The speechifying of unity based on amnesia has been given precedence over the real mechanisms that promote peace building and reconciliation. Indemnities, amnesties and presidential pardons have been used to protect perpetrators of conflict and violence at the expense of justice. (Benyera and Ndlovu-Gatsheni, 2015)

In addition those in government known to have committed or were part of the crimes have not taken responsibility for their past actions. There are no public apologies that have been issued in acknowledgement of their wrongdoing except Mugabe's near apology when he said Gukurahundi was "an act of madness." Furthermore, the NPRC has a lifespan of ten years five of which expired before its work commenced. The short lifespan of the commission is perceived as an attempt to do a substandard process with no sustainable impact. After decades of existence as a sovereign post-colonial nation, Zimbabwe is still desperately seeking a well-thought-out truth, justice and reconciliation mechanism (Benyera and Ndlovu- Gatsheni, 2015)

The NPRC is not adequately funded resulting in crucial Transitional Justice activities such as the development of an Early warning system, truth telling, compensation and trials undone. The NPRC remains inaccessible to victims as its offices have not been decentralised due to lack of resources. The NPRC offices are located in the capital city of Harare and in Bulawayo the second largest city. Many victims lack the resources to travel to the NPRC offices to access the services. The visibility of the NPRC remains a major bottleneck to the success of its work. People living in rural areas are not aware of the existence of neither the commission nor its mandate, hence the need to increase visibility and a deliberate targeting of rural communities with relevant information.

\section{BACKGROUND OF THE POLICY}

Through Section 251 of the 2013 Constitution the Government of Zimbabwe adopted the policy of healing and reconciliation. The NPRC was established to implement the policy. The National Peace and Reconciliation Commission Act [Chapter 10:32] of 2017 was put in place to operationalise the National Peace and Reconciliation Commission; to confer additional jurisdiction on the Commission, including its investigative powers; to provide for the terms of office, conditions of service, qualifications and vacation of office of Members of the National Peace and Reconciliation Commission and the appointment of the Executive Secretary; and to provide for matters connected with or incidental to the foregoing (NPRC Act Chapter 10:32).

The main functions of the NPRC according to the Constitution of Zimbabwe (2013) are as follows:

(a) To ensure post-conflict justice, healing and reconciliation;

(b) To develop and implement programmes to promote national healing, unity and cohesion in Zimbabwe and the peaceful resolution of disputes;

(c) To bring about national reconciliation by encouraging people to tell the truth about the past and facilitating the making of amends and the provision of justice;

(d) To develop procedures and institutions at a national level to facilitate dialogue among communities in order to prevent conflicts and disputes arising in the future;

(e) To develop programmes to ensure that persons subjected to persecution, torture and other forms of abuse receive rehabilitative treatment and support;

The major flaw of the healing and reconciliation policy was evident in the ten years allocated to the NPRC to resolve the deep rooted conflicts affecting Zimbabwe. The country has a history of unresolved conflicts and cosmetic attempts to address those leaving victims with no hope for recourse. The NPRC took more than five years to start thereby eating half of its term in office. It 
effectively means that the NPRC does not have enough time to implement an effective peace and reconciliation in Zimbabwe. The lack of impetus by the government of Zimbabwe to operationalise the NPRC is an indicator of its lack of honest and genuineness to address conflicts in Zimbabwe.

\section{PUBlic InTEREST AND POLICY IMPACT}

Bloomfield (2003) points out that processes of reconciliation, integration and national healing should involve whole communities if they are to be effective. This is because 'entire communities who have to begin to reorient themselves from the adversarial, antagonistic relations of war to more respect-based relations of cooperation'. If sectors of the affected communities are excluded from the processes the effectiveness of the process is minimal. The effectiveness of the NPRC is measured on the involvement and participation of stakeholders in the reconciliation process in Zimbabwe. Reconciliation policy must not be centralised or formulated at the top level without the participation of the grassroots. The impact of the reconciliation policy in Zimbabwe is limited as victims and other stakeholders feel excluded from the process. The continued episodes of violence and the impunity of perpetrators in full view of the NPRC make the public to question the real impact of the reconciliation policy in Zimbabwe.

\subsection{The Exclusion of Victims in Reconciliation Processes}

Zimbabwe has a history of implementing cosmetic healing and reconciliation policies which do not effectively deal with past atrocities. Victims and survivors of violent episodes in Zimbabwe continue to suffer in silence as they wait for justice. A country which does not deal with its ugly past will face a haunting future. Mamdani (2015) argues that 'survivor's justice' is efforts towards political reform rather than the traditional post-1945 Nurembergcriminal justice which classifies people as victims and perpetrators. In survivor's justice, people coming out of a conflict are together understood as survivors who are crying out for a new society characterised by political reform and peace building. However, Zimbabwe is still at a stage where perpetrators and victims are in two distinct camps. The perpetrators are firmly in control of political power and are wary of genuine healing and reconciliation. On the other hand victims are yearning for genuine reconciliation to heal the wounds of past atrocities.

Victims are the most affected by the success or failure of the healing and reconciliation policy in Zimbabwe. Some individuals affected by the Gukurahundi are bitter and angry about their experience and are interested in seeking revenge. One of the victims said, "We need revenge given a chance, I would also inflict the same pain and the best is to do the worst to them" (Muchacha, 2016). Victims of operation Murambatsvina still harbor ill feelings against the government. The operation caused serious humanitarian effects, such as homelessness, hunger, starvation, loss of property and livelihoods. Like other human rights crises, women and children were the most affected. Anna Tibaijuka the UN monitor concluded that the operation was carried out in an indiscriminate and unjustified manner, with indifference to human suffering, and, in repeated cases, with disregard to several provisions of national and international legal frameworks (Tibaijuka, 2005).
During the pre- and post-2008 election period in Zimbabwe, a high number of politically motivated violence incidences were recorded. These included torture, disappearances, intimidation, sexual violence and seizure and destruction of property. Ploch, (2010) notes that in 2007, there were 603 reported incidents of torture, 865 incidents of assault, and 2766 reports of arrest and detention. According to Human Rights Watch (2008) from November 2007 to March 2008, there were 1775 reported incidents of political violence in Zimbabwe. The perpetrators of the violence were mainly state actors and the victims were opposition political supporters.

\subsection{Absence of Truth Telling}

Episodes of past violence in Zimbabwe are shrouded in mystery. The lack of truth telling is a characteristic of the reconciliation policy in Zimbabwe. The true about the liberation struggle, Gukurahundi, Murambatsvina and the violence during election periods have never been told. The truth is not told and it remains hidden or it's told from the perspective of the alleged perpetrators that have the reins of power. Rosenberg in Huyse (2003) warns:

If the victims in a society do not feel that their suffering has been acknowledged, then they are not ready to put the past behind them. If they know that the horrible crimes carried out in secret will always remain buried then, they are not ready for reconciliation. Then the truth is one-sided and distorted. As a result the wounds remain open.

If there is no truth telling there is there any meaningful reconciliation. The reconciliation policy is therefore viewed by the public as a way to suppress the truth and create a false narrative to protect the perpetrators from justice. The NPRC can learn from South Africa's Truth and Reconciliation Commission (TRC) and the Rwanda's use of indigenous methods of reconciliation to promote truth telling. Victims of all episodes of violence in Zimbabwe must be given a platform to tell their stories by the NPRC.

\subsection{Perpetuation of abuse and violations}

Since its inception the NPRC has been invisible in early warning and prevention of violence in Zimbabwe. This gives a public perception that the NPRC is ineffective. The abduction, torture and disappearance of human rights activists have become a normal in Zimbabwe. Itai Dzamara disappeared in March 2015 and has never been found. Opposition political party members MP Joana Mamombe, Cecilia Chimbiri and Netsai Marova were abducted in May 2020 and were found dumped two days later with injuries. The NPRC did not investigate the disappearances, abductions and torture leading to uncertainty about its legitimacy as a peace and reconciliation body. (Murambadoro, 2019).On August 1, 2018 six unarmed civilians lost their lives and several others were wounded when soldiers opened fire on citizens protesting alleged misconduct by the Zimbabwe Electoral Commission (ZEC).

The NPRC is absent during crucial moments of political violence and human rights violations. Hence its relevance and impact in Transitional justice in Zimbabwe is not felt. The NPRC has even failed to speak out against violence or to put out press statements calling for justice and peace. The above evidence concurs with Huyse (2003) when he argues that 'silence and 
amnesia are the enemies of justice'. The NPRC must therefore speak up against the culture of violence and put in place mechanisms for early warning and violence prevention.

\section{Challenges With the National HeAling AND RECONCILIATION POLICY}

The NPRC as a healing and reconciliation policy has flaws. It is a cosmetic attempt to healing and reconciliation through the provision of a blue print but without the actual action on the ground. The NPRC with its short lifespan has so far done little to justify its existence. Critical aspects of healing and reconciliation such as truth-telling, justice and accountability are lacking on the ground. The NPRC which is supposed to spearhead the process is not visible and the affected communities are not aware of its existence or its mandate.

\subsection{Lack of Political Will}

There appears to be a lack of political will by the government to implement the healing and reconciliation policy. Benyera and Ndlovu- Gatsheni (2015) argue that one of the biggest challenges facing the healing and justice mechanisms in Zimbabwe is the conundrum of using the state organs to prosecute the state, which is itself believed to be a perpetrator of gross violations of human rights. Hence the state shows no willingness to fully implement the policy out of fear of prosecution. Since its inception, the NPRC has not been visible in communities affected by episodes of violence. Its programmes have not reached the intended beneficiaries in rural communities. The NPRC offices are situated in Harare and Bulawayo making them inaccessible to citizens due to transport costs. The government has not shown enough political will to implement the national reconciliation policy. The funding of the NPRC has not been prioritised and the lack of funding remains a stumbling block to its work.

\subsection{Exclusion of Key Stakeholders}

The exclusion of stakeholders such as survivors, faith based organisations, civic society and traditional leaders in the NPRC processes is a major weakness of the healing and reconciliation policy in Zimbabwe. In countries such as Rwanda and South Africa stakeholders played a critical role in aiding the process of reconciliation. The media raised citizen awareness on the process thereby increasing citizen participation. The NPRC appears to have adopted a top to bottom approach where decisions and programme implementation is determined by decision makers at the top without the involvement of the people affected by conflict in various communities.

Stakeholders such as victims, traditional leaders, faith leaders and opposition political parties feel that they are excluded in the reconciliation process. Lack of consultation and participation of stakeholders in the process pose a challenge to genuine reconciliation and sustainable peace in Zimbabwe. Huyse (2003) highlights that for peace and reconciliation to win, both victims and perpetrators of and violence have to be part and parcel of reconciliation, national healing and integration activities. Victims must be given the opportunity to tell their stories and decisions must not be made on their behalf. The role of traditional methods of transitional justice must be explored and given a chance to succeed. Western methods of transitional justice have been given prominence over traditional methods and at times implemented in contexts where they do not work. Traditional leaders must therefore be included in the healing and reconciliation processes by the NPRC in Zimbabwe.

\section{THE GOVERNMENT Position ON THE HEALING AND RECONCILIATION POLICY}

The Government of Zimbabwe through the NPRC views its efforts as holistic and multidimensional in bringing reconciliation through unity and cohesion. It argues that the healing and reconciliation policy is people centred as it was created through the 2013 people driven constitution. According to the NPRC it hopes to achieve national healing and reconciliation through the following strategies:

1. Consensus building and dialogue: through the engagement between citizens and their leaders to explore the best possible ways of healing and reconciliation. The processes will be inclusive to build trust and it will include women, youth and people with disabilities.

2. Truth telling: The Commission will encourage citizens to tell the truth about the past. This is critical in healing and restoration. This will be undertaken through multiple approaches provided for in the Act.

3. Mainstreaming cross-cutting approaches: The Commission will mainstream cross-cutting principles that affect healing and reconciliation such as human rights-based approach and gender equity.

4. Legislative and policy analysis: The Commission will identify key policy needs and gaps appropriate for the promotion of peace and cohesion. It will recommend alternative policies that enable a peaceful environment and guarantee no recurrence of conflict.

5. Institutional strengthening and capacity building: For purposes of sustainability there will be the strengthening of institutions and human capacities of the NPRC and other stakeholders such as traditional leaders.

6. Partnerships building: The Commission will align all partners working towards healing and reconciliation around a unifying and multi-sectoral peace framework that sets harmonised benchmarks for the peace architecture.

It must however, be noted that the NPRC have an excellent blueprint but the execution is nonexistent on the ground. Murambadoro (2019) observes that the Zimbabwean government has a history of ostensibly coming up with cosmetic changes such as the Unity Accord of 1987 as healing and reconciliation policies. However, these policies eventually fail as they are not inclusive of other stakeholders and are not aimed at genuine healing and reconciliation. The genuineness of the government's policy must not be measured by the gloss of its blue print but by the effectiveness of its action on the ground. Machakanja (2010) notes:

"It is only after truth-seeking initiatives have taken place, that willingness to seek justice based on people's understandings of what happened to them can be achieved. Thus, it is important that the state takes concrete policy actions to demonstrate a break with the past and build a future based on respect for human rights and rule of law." 
The government of Zimbabwe must walk the talk regarding the implementation of the policy of peace and reconciliation. Political will to implement the policy must be evident by action on the ground.

\section{DIFFERENT GROUPS PERCEPTIONS OF POLICY}

There are different viewpoints on how the policy of healing and reconciliation is perceived in Zimbabwe. The state, civic society, faith based organisations and victims have diverse views on how the process should be implemented and who should be involved. Machakanja (2010) rightly observes the existence of contested viewpoints over the construction and ownership of the process of national healing. Divergent views on healing and reconciliation are emerging at local, national, regional and international levels.

\subsection{Victims Perception}

For some victims in Zimbabwe, the NPRC has resuscitated hope for victims in that it is functional with workers on the ground and a national office. It has also managed to come up with provincial peace committees that are to implement programmes in the communities However, the publicity of the NPRC has been very poor to the extent that victims are not aware of its existence and its functions. Affected communities situated in rural areas of Matebeleland and Midlands Province hardly know of the NPRC. The composition of the NPRC is an issue of contention as it is lacking the inclusion of victims. The eight Commissioners were appointed by the president whom the victims view as having played an active role in the atrocities. The appointment of the Commissioners therefore raises questions on the impartiality and independence of the NPRC.

The victims feel there is lack of political will to implement healing and reconciliation by the state. The fact that the NPRC has not been adequately advertised, funded and given a long lifespan is pointed out as evidence of the government's unwillingness to address the issue. The healing and reconciliation narrative is Zimbabwe is viewed from a partisanship angle at the expense of national interests.

According to Machakanja (2010) there are strong views from victims that atrocities committed against civilians cannot simply be swept under the carpet under the excuse of preserving national cohesion and unity during. The perpetrators must be brought to justice, and if individuals are to be forgiven, it must be done publicly as part of a transparent truth, justice and reconciliation process.

\subsection{Civic Society Views}

Civic society organisations are of the opinion that the NPRC should be accommodative and inclusive of all people regardless of race, colour, creed or nationality. There should be a non partisan justice delivery system for effective healing and reconciliation. Civic society activists have already protested against the activities of the NPRC. Two of its public meetings in Bulawayo and Lupane disrupted as people felt the Commission wanted to protect powerful people from prosecution for the Gukurahundi atrocities. In Harare, similar disturbances occurred at a Southern African Political Economy Series (SAPES) policy discussion on national healing and reconciliation in Zimbabwe. (Tshuma, 2018) Civic
Society Organisations argue that Section 10 of the NPRC Act undermines healing and reconciliation. The section empowers the Minister of National Security to block an investigation by issuing a certificate blocking disclosure of evidence and documentation that they may deem to be prejudicial to the defense, external relations, internal security or economic interests of the state. According to Benyera and Ndlovu-Gatsheni (2015) the role of civil society is to complement the efforts of the state. This could take various forms, such as raising awareness, disseminating information, establishing education programmes around the work of the Commission.

Victims and Civic society organisations interpret the healing and reconciliation policy from the same viewpoint. They feel that as long as there is no political reform healing and reconciliation will not be achieved. The perpetrators of the several atrocities that took place in Zimbabwe still hold political power and are an impediment to justice, peace and reconciliation. There is lack of political will to implement government decisions in Zimbabwe which paralyses state departments, rendering them incapable of following clearly articulated government policies such as the operationalisation of Commissions (Benyera and NdlovuGatsheni, 2015)

\subsection{Women}

Most women in Zimbabwe are victims of conflict starting from the liberation struggle, Gukurahundi, Murambatsvina and political violence. Women such as Jestina Mukoko, Joana Mamombe, Cecilia Chimbiri and Netsai Marova have been victims of state torture and brutality. Women have suffered the negative effects of conflict such as rape, sexual abuse, unwanted pregnancies and torture. According to a Zimbabwe NGO Forum report (2011):

The aftermath of 2008 elections was one of the most notable upticks in political violence in the last 10 years. Women were raped and forced into concubinage as a means of punishing them or their spouses for participating in politics. Testimonies of survivors revealed numerous cases of rape, gang rape, torture, intentional transmission of HIV, and sexual slavery in ZANU-PF base camps. Perpetrators of these crimes were met with impunity as police refused to document these reported crimes either because they did not want "to interfere in political issues"

Women in Zimbabwe view the NPRC as an opportunity to address the issues affecting women in conflict situations. However, the NPRC has given them a false hope as they have not been able to realise the benefits of the reconciliation process. Victims of political violence yearn for justice whilst known perpetrators enjoy the benefits of impunity. The implementation of UNSC Resolution 1325 has strengthened the role played by women in peace and security in Zimbabwe. Women in Zimbabwe play a critical role in peace building. They are involved in activities that work towards community healing and reconciliation (UN Women, 2014).

\subsection{Church}

The church in Zimbabwe views the policy of reconciliation differently. Church bodies that are aligned to the state view the current policy as a work in progress that will eventually result in peace and stability. Other church bodies have an alternative view point. A statement from the Joint Conference Church and 
Development (2019) stated that the people in Zimbabwe are not sufficiently protected against violence, despotism and injustice by state structures. The churches view themselves as a neutral force that offers room to openly discuss the situation in Zimbabwe and make a significant contribution to the development of functioning civil society structures.

According Dube (2018) the role played by the armed forces in the ending of the Mugabe regime as well as before and after the elections of 30 July 2018 is therefore particularly alarming. Zimbabwe sees itself in a crisis whose dimensions are not only political and economic, but also moral and spiritual

In all the episodes of violence in Zimbabwe, some church organizations have been vocal against state brutality. They have called for the end to impunity and called for justice for the victims. On the other hand other church groups have been either indifferent or had been recruited by the political parties. The Catholic, Protestant and Evangelical Bishops have played a critical role in mediation and peace building in Zimbabwe. They have appealed several times to the SADC, the African Union and the UN to intervene in the Zimbabwe crisis.

\section{The AFricAN Union Position ON CONFLICT}

Article 12 of the PSC Protocol relating to the Establishment of the Peace and Security Council (PSC) provides for the establishment of a Continental Early Warning System (CEWS), in order to facilitate the anticipation and prevention of conflicts in Africa (African Union Report, 2010). The CEWS consists of an observation and monitoring which is responsible for data collection and analysis. There are Regional Mechanisms for Conflict Prevention, Management and Resolution, which are to be linked directly to the observation and monitoring unit which is called the "Situation Room".

The Framework for the Operationalization of the CEWS was endorsed by the 10th Ordinary Session of the Executive Council, held in Addis Ababa, in January 2007. The CEWS is responsible for data collection and analysis and is mandated to collaborate with the United Nations (UN), its agencies, other relevant international organizations, research centres, academic institutions and Nongovernmental Organizations (NGOs) with its information to be used by the Chairperson of the Commission to advise the Peace and Security Council (PSC), on potential conflicts and threats to peace and security in Africa and recommend the best courses of action (African Union Commission, 2006). As part of the African Union and as a member of SADC Zimbabwe must ensure that it has a functional Conflict Early Warning And Response System (CEWARS) in line with demands of the continental and regional bodies. The NPRC has not been able to come up with a CEWARS which is crucial in a country where conflict is prevalent such as Zimbabwe. The CEWARS will ensure that hot spots of conflict are identified and resources are mobilised in time to respond to possible conflicts and that there is coordinated response and collaboration between responsible authorities and affected communities.

The African Union recognises the importance of peace and security in Africa. According to the African Union (2015) the body recognises that peace and security is indispensable for the success of the continent's development agenda. Countries that are affected by conflict and those coming from conflict should prioritize peace and security to enhance their development. The $\mathrm{AU}$ encourages member states to address root causes of conflict by:

Tackling economic and social inequalities and exclusion; strengthen good and inclusive governance; fight against all forms of discrimination; and forge unity in diversity through democratic practices and mechanisms at the local, national and continental levels.

Zimbabwe's peace and reconciliation policy is in line with the AU's peace and security agenda. Like the AU, the NPRC aims to identify key policy needs and gaps appropriate for the promotion of peace and cohesion. It will recommend alternative policies that enable a peaceful environment and guarantee no recurrence of conflict (NPRC, 2013). SADC and the AU have been involved in the efforts to promote peace and security in Zimbabwe as regional bodies. SADC successfully mediated the Global Political Agreement between political parties in Zimbabwe in 2008 enhancing peace and security in the country.

\section{SOlving ThIS Policy PROBlem}

Citizens and stakeholders have different viewpoints on solving the healing and reconciliation quagmire in Zimbabwe. There is a general feeling among citizens that there should be an enabling environment for an effective process. The current environment is polarized and the policy is viewed through ethnic and political lenses. A conducive environment for healing and reconciliation must be created.

Victims feel there is a culture of the lack of accountability by perpetrators which continues to affect healing and reconciliation. The NPRC has done little to address the issue of continued violence. There are unresolved issues such as the disappearance of activists like Itai Dzamara, killings of protesters by armed security forces on 1 Aug 2018, and 14 January 2019 protests. The lack of action by the state and the NPRC to bring the perpetrators to account and justice for victims is an indicator that the reconciliation process in Zimbabwe is flawed. Accountability and justice must be pillars for an effective healing and reconciliation policy. The culture of violence must be stopped for citizens to have trust in the whole process.

The civic society in Zimbabwe has been calling for a longer lifespan for the NPRC. The NPRC has already used half of ten year lifespan and yet little has been achieved on the ground. The civic society is calling for political will on the part of the Zimbabwe government to implement the peace and reconciliation policy.

According to Machakanja (2010) traditional leaders are effective in linking of both the perpetrator and the victims at community level. They can also lead local grassroots mechanisms such as customary law courts to act against lower level offenders. Spiritually they can perform certain rites, rituals and ceremonies such as the case of Rwanda. The temporary nature of the NPRC calls for the involvement of community based structures in the healing and reconciliation process for sustainability. Traditional leaders should be involved in the peace and reconciliation process in Zimbabwe as they offer traditional methods of transitional justice which can be effective in resolving conflict in the Zimbabwe context. 
The Government of Zimbabwe must do its constitutional mandate of ensuring that the reconciliation policy is rolled out. An adequate budget must be availed to the NPRC for its operations. The involvement of communities and stakeholders must be promoted for an effective and sustainable reconciliation process. Important groups such as women, churches, traditional leaders, survivors, and perpetrators must be at the centre of the process. The government must ensure an all inclusive reconciliation process. The issue of justice for survivors and accountability for the perpetrators must be addressed.

\section{RECOMMENDATIONS}

The healing and reconciliation policy in Zimbabwe needs to consider the following recommendations from a policy and governance perspective for it to be effective and efficient:

1. Independence of Commission: The NPRC must maintain its independence from the state for it to achieve its mandate and objectives. If it is not independent then state interference will result in an opaque process where perpetrators are protected and justice for victims elusive. The appointment process in Zimbabwe, particularly with regards to the appointment of the Chairperson of the NPRC by the president raises questions about its impartiality.

2. Visibility and Accessibility: The commission must ensure that its work is visible and the public is aware of its activities. Most affected communities in the rural areas are not aware of the existence of the NPRC and its mandate. The commission must partner with traditional leaders, faith based organisations and the media to enhance its visibility. The accessibility factor requires that the NPRC must be accessible to citizens, with the public having knowledge of the institution and its physical location, and with diversity of composition. The accessibility of the NPRC is crucial in order to ensure that victim can seek redress.

3. Resources: For the NPRC to discharge its duties effectively, the government needs to ensure that the Commission has adequate resources, its members are adequately remunerated, that the institution itself is financially independent, and that any public funds should not be under the direct control of the government. However, due to the severe economic challenges in Zimbabwe, the ability of the NPRC to function effectively has been adversely affected over the years. Such challenges have had a negative impact on the Commission.

4. Accountability: The NPRC must ensure that perpetrators are held accountable for their actions during the healing and reconciliation process.

5. Demilitarisation: A key finding from the provincial consultations, which is also echoed in literature and civic reports, is a militarization of communities and civilian spaces over the years. This has undermined the capacity of key public institutions to deliver services in line with the constitution, undermining their independence. With this, citizens' trust and confidence in public institutions have been eroded over time.- NPRC Strategic Plan
(2018). The state must ensure that there is demilitarization for true and effective healing and reconciliation.

6. Impartial judiciary: Is an important and integral part of any healing and reconciliation process. The respect and independence of the judiciary by the executive in Zimbabwe must be improved. In some instances the executive refused to enforce certain court orders that are seen to be unfavourable to the state or the ruling ZANU PF party. Such behaviour erodes public trust in the fairness and independence of the justice system.

7. Transformative and Restorative justice: The Zimbabwe situation is unique in that the alleged perpetrators of atrocities are still in power. Hence the use of criminal and retributive justice will hit a brick wall. Rather transformative and restorative justice who seeks to restore and heal the victim.

8. Stakeholder involvement: The NPRC must involve crucial stakeholders such as traditional leaders, faithbased organisations, survivors and civic society organisations for consensus building and visibility.

9. Grief and Trauma handling: Due to the magnitude of violence suffered and the number of years taken to address healing and reconciliation in Zimbabwe, there is huge amount of work that has to be done. Grief and trauma cases dating back to the war of liberation, Gukurahundi and Murambatsvina need to be dealt with by professional social workers and counselors.

10. Establishment of Conflict Early Warning Systems (CEWERS) - One of the mandates of the NPRC is to establish a CEWERS. This must be prioritized to prevent the occurrence of further conflicts.

\section{CONCLUSION}

The NPRC offers Zimbabwe an opportunity to rethink and restrategise on national healing and reconciliation. The major challenge facing healing and reconciliation in Zimbabwe is that the state which is supposed to champion national reconciliation and healing is alleged to be the perpetrator of the atrocities. Therefore there is need for the NPRC to ensure that an approach that is inclusive and results in restoration of the victim. The inclusion of communities and stakeholders in the reconciliation process is vital for a successful and sustainable process. Further, the Government of Zimbabwe must show the political will to roll out the policy and reach out to victims and survivors. The culture of perpetual violence and impunity must be addressed to demonstrate that the government is serious about peace and reconciliation. Past atrocities and episodes of violence should be openly discussed and a way forward agreed. Transitional justice should be a central theme of peace and reconciliation in Zimbabwe.

\section{REFERENCES}

[1] Aiken, N. T. (2013). Rethinking reconciliation in divided societies. Transitional Justice Theories, 40.

[2] Bloomfield, D., Barnes, T., \& Huyse, L. (Eds.). (2003). Reconciliation after violent conflict: A handbook. International Idea. 
[3] Buckley-Zistel, S., Beck, T. K., Braun, C., \& Mieth, F. (Eds.). (2013). Transitional justice theories. Routledge.

[4] Catholic Commission for Justice, Peace in Zimbabwe, \& Legal Resources Foundation (Zimbabwe). (1997). Breaking the Silence, Building True Peace: A Report on the Disturbances in Matabeleland and the Midlands, 1980 to 1988. Catholic Commission for Justice and Peace in Zimbabwe.

[5] Dube, E. (2018). Violence, Justice and Peace in Zimbabwe: An Appraisal of Mugabe's Legacy through the Publications of Roman Catholic Church Organs in Zimbabwe. The End of an Era? Robert Mugabe and a Conflicting Legacy, 247.

[6] "Gender-based Violence in Zimbabwe," Zimbabwe Human Rights NGO Forum. No. 68. 2011. Pg. 2. http://www.hrforumzim.org/wpcontent/uploads/2012/03/Gender-based-violence-in-Zim-WT20497.pdf

[7] Howard-Hassmann, R. E. (2010). Mugabe's Zimbabwe, 2000-2009: Massive human rights violations and the failure to protect. Hum. Rts. Q., 32, 898.

[8] Huyse, Luc 2003. Zimbabwe: Why reconciliation failed. In: Bloomfield, Barnes and Huyse,

[9] International Peace Institute, (2012). Preventing Conflicts in Africa: Early Warning and Response. Retrieved from https://www.ipinst.org/wpcontent/uploads/publications/ipi_e_pub_preventing_conflicts.pdf

[10] Machakanja, P. (2010). National healing and reconciliation in Zimbabwe: Challenges and opportunities.

[11] Mamdani, M. (2015). Beyond Nuremberg: The historical significance of the post-apartheid transition in South Africa. Politics \& Society, 43(1), 61-88.

[12] Mani, R. (2002). Beyond retribution: Seeking justice in the shadows of war (pp. 47-48). Cambridge: Polity Press.

[13] Mihr, A. (Ed.). (2012). Transitional Justice: Between Criminal Justice, Atonement and Democracy. SIM.

[14] Miller, Z. (2008). Effects of invisibility: In search of the 'economic' in transitional justice. The International Journal of Transitional Justice, 2(3), 266-291.

[15] Muchacha, M. (2016). Politically motivated violence (PMV) in Zimbabwe and the role of social work. Journal of Human Rights and Social Work, 1(4), 156-164.

[16] Murambadoro, R., 2019. One year after has the national Peace and Reconciliation Commission Act failed Zimbabweans- https://kujengaamani.ssrc.org/2019/02/07/
[17] Nagy, R. (2008). Transitional justice as global project: Critical reflections Third World Quarterly, 29(2), 275-289.

[18] Ndlovu-Gatsheni, S. J. (2012). Rethinking Chimurenga and Gukurahundi in Zimbabwe: A critique of partisan national history. African studies review, 55(3), 1-26.

[19] Ndlovu-Gatsheni, S., \& Benyera, E. (2015). Towards a framework for resolving the justice and reconciliation question in Zimbabwe. African Journal on Conflict Resolution, 15(2), 9-33

[20] Oomen, B. (2005). Donor-driven justice and its discontents: The case of Rwanda. Development and Change, 36(5), 887-910.

[21] Ploch, L. (2010, July). Zimbabwe: The transitional government and implications for US policy. LIBRARY OF CONGRESS WASHINGTON DC CONGRESSIONAL RESEARCH SERVICE.

[22] Teitel, R. G. (2000). Transitional justice. Oxford University Press on Demand.

[23] Tibaijuka, A. K. (2005). Report of the fact-finding mission to Zimbabwe to assess the scope and impact of Operation Murambatsvina.

[24] Tshuma, D. (2018). Reconciliation, integration and healing efforts in Zimbabwe. Conflict trends, 2018(2), 19-26.

[25] Union, A. (2014). Common African Position (CAP) on the post-2015 development Women,

[26] U. N. (2014). Annual Report 2013-2014.agenda. Addis Ababa.

\section{AUTHORS}

First Author - Ched Nyamanhindi is a PhD student at the Institute of Peace, Leadership and Governance (IPLG) at Africa University. He holds a Masters in Peace and Governance (Africa University 2013). Ched has keen interest in the areas of peace and security.

Corresponding Email:

nyamanhindic@africau.edu/mugoven@gmail.com 